\title{
sciendo
}

\section{Effects of Flywheel Resistance Training on Sport Actions. A Systematic Review and Meta-Analysis}

\author{
by \\ Javier Raya-González¹, Amaya Prat-Luri², Alejandro López-Valenciano, \\ Rafael Sabido², Jose Luis Hernández-Davó ${ }^{1}$
}

\begin{abstract}
The purpose of the present meta-analysis was to examine the effect of flywheel resistance training (FRT) on main sport action (i.e., jumping performance, sprinting time and change of direction performance) improvements in athletes and healthy active people. A Boolean search strategy adapted for each of the databases employed was conducted to identify all studies measuring change in sport actions performance after FRT interventions up to July 2019. Outcomes were analysed using an average effect size $\left(D_{+}\right)$and a $95 \%$ confidence interval $(C I)$, which was calculated assuming a random-effects model. A total of 9 studies with 283 participants met the inclusion criteria and were selected for the analysis. The mean quality score (PEDro scale) of the articles included in the meta-analysis was 5.67. The metaanalysis showed significant positive effects on jumping performance (SMC 0.65; 95\% CI, 0.11-1.19; $p=0.02$ ), sprinting time (SMC 1.33; 95\% CI, 0.39-2.28; $p<0.01$ ) and change of direction performance (SMC 1.36; 95\% CI, $0.58-2.14 ; p<0.01)$ after FRT interventions compared to control/traditional resistance training groups. The results of the present meta-analysis provide evidence of the usefulness of FRT to improve variables related to sport performance in both athletes and healthy population.
\end{abstract}

Key words: iso-inertial, performance, sprint, jump, change of direction.

\section{Introduction}

Maximal power output can be defined as the explosive nature of force production (Hakkinen et al., 1985). Previous research has supported the fact that a superior ability to generate maximal power is related to a better athletic performance (Cormie et al., 2011). The reasoning behind this is that some actions related to performance in sports (e.g. sprinting, jumping and change of direction [COD]) require high strength and power produced by the muscles of the lower limbs (Wisløff et al., 2004). In this sense, a strong relationship between lower-limb power output and most of the above-mentioned typical sport actions has been reported (González-Badillo et al., 2015; Swinton et al., 2014). Thus, in order to optimize performance adaptations, there is a need to find resistance training methodologies that lead to power output increases.

Traditionally, both in research and practice, the most common resistance training methodologies used entail a predominant incidence in the concentric (CON) phase, such as free weights and weight stack machines (Fernandez-Gonzalo et al., 2014). As the force that muscles are able to produce during an eccentric (ECC) action is greater than that produced during the CON phase, the ECC phase is usually underloaded during traditional resistance training. However, compared to both $\mathrm{CON}$ and isometric traditional training, ECC resistance training methods have been shown to produce greater improvements in mechanical function (e.g.

1 - Faculty of Health Sciences, Isabel I University, Burgos, Spain.

2 - Department of Sport Sciences, Sport Research Center, Miguel Hernández University, Elche, Spain. 
stiffness), morphological changes (e.g. muscular hypertrophy), neuromuscular adaptations (e.g. motor unit firing frequency) and dynamic athletic performance due to the higher loads generated during the ECC phase of the movement (Suchomel et al., 2018).

Among the methods that emphasize the ECC action, iso-inertial devices, which are based on the Flywheel Paradigm (Berg and Tesch, 1994), should be highlighted. This paradigm implies that the force applied during the CON phase of the movement unwinds a cord/strap connected to a shaft with the rotating flywheel, which starts to rotate and store energy. Kinetic energy will increase as a function of the inertial load used and the rotational speed achieved. Once the whole range of motion of the $\mathrm{CON}$ action is performed, the cord/strap rewinds and the person must resist the pull of the rotating flywheel/s by performing a braking ECC muscle action (Maroto-Izquierdo et al., 2017). When performed correctly (delaying the braking action to the last phases of the ECC action), flywheel devices allow to produce the socalled eccentric-overload (EO) (RomeroRodriguez et al., 2011). Hence, higher force levels are produced in the ECC phase compared to the CON phase of the movement (Norrbrand et al., 2008; Núñez et al., 2017).

The effects produced by flywheel exercises during resistance training have been extensively investigated. In this regard, several studies have obtained positive results in injury prevention programs (Askling et al., 2003; de Hoyo et al., 2015), rehabilitation processes after injuries (Romero-Rodriguez et al., 2011), strength gains (Norrbrand et al., 2008), and early muscular hypertrophy (Tesch et al., 2004). All these results have a great impact on both healthy and nonhealthy populations. In addition, strong research also supports the effectiveness of flywheel resistance training (FRT) programs in sport activities. Specifically, research has shown performance improvements in sports that imply actions such as jumping (de Hoyo et al., 2015; Sabido et al., 2017; Tous-Fajardo et al., 2016), sprinting (de Hoyo, et al., 2015; Gonzalo-Skok et al., 2017) and COD (de Hoyo, et al., 2015; Núñez et al., 2018; Tous-Fajardo et al., 2016).

As a result of the increased interest regarding FRT interventions, some meta-analyses have been recently published (Nuñez and Sáez de
Villarreal, 2017; Vicens-Bordas et al., 2018). All these meta-analyses are mainly focused on the improvement of muscle strength and increases in the muscle cross sectional area. Nevertheless, flywheel devices are usually employed in sport populations, aiming at improving dynamic athletic performance. To the best of the authors' knowledge, the current study is the first investigation to provide Level 1 evidence of the benefits of FRT to the improvement of the abovementioned main sport actions in healthy active people and sport populations. Therefore, the aim of this study is to systematically review and, if possible, conduct a meta-analysis to analyze the effects of FRT on chosen activities (i.e., sprinting, jumping and COD ability) related to sports performance.

\section{Methods}

This meta-analysis was carried out following the recommendations and criteria established in the Preferred Reporting Items for Systematic Reviews and Meta-analysis (PRISMA) statement guidelines (Moher et al., 2009).

Study selection

The present meta-analysis had the ensuing inclusion criteria: a) the experimental design in the study had to last more than 4 weeks; b) the study had to be carried out by at least two groups (one control or traditional resistance training group and one FRT group); c) studies had to compare effects of FRT in at least one of the following variables: change of direction, jumping and/or sprinting; d) participants in the study had to be adults (aged $\geq 17$ years); e) participants in the study needed to be experienced in strength training; f) the study had to report enough statistical data to calculate the effect sizes. Studies with injured participants or patients with any pathology or pain at the moment of the study were excluded. Literature reviews, abstracts, editorial commentaries, and letters to the editor were also excluded. Lastly, some authors were contacted to collect missing data or to clarify if data were duplicated in other publications. Incomplete data or data from an already included study, were excluded.

Search strategy

Studies were identified through a Boolean search strategy adapted for each of the databases employed (PubMed, Sportdiscus, the Cochrane 
Central Register of Controlled Trials and Web of Science). The search terms can be consulted in Appendix 1 and they were limited to publication dates (up to 9/07/2019). To avoid the loss of potential studies, the reference lists of the studies recovered were also consulted. Two reviewers (J.R. and A.P.) independently: a) screened the title and abstract of each reference to locate potentially relevant studies, and once full-text of the screened documents was obtained; b) reviewed the documents in detail to identify articles that met the selection criteria. A third external reviewer (A.L.) was consulted to resolve discrepancies in the selection process.

Data extraction and quality assessment

With the aim of guaranteeing the maximum objectivity possible, a codebook that specified the standards followed in coding each of the characteristics of the studies was produced. The moderator variables of the studies selected were coded and grouped into three categories according to Lipsey (2009) recommendations: substantive (participants, context and treatment), methodological and extrinsic variables. Appendix 2 displays a brief description of the moderator variables coded separated by the category. For the present meta-analysis, the outcomes assessed were related to jumping performance, sprinting time and COD performance.

The methodological quality of the studies selected was evaluated using the Physiotherapy Evidence Database Scale (PEDro) (Sherrington et al., 2000). The reviewed articles were awarded one point for each criterion that was clearly satisfied, up to a maximum of 10 points. The methodological quality of the study was categorized as follows: a score ranging from 6 to 10 was indicative of high quality; whereas scores of 4-5 indicated fair quality; and scores $\leq 3$ indicated poor quality (Valkenet et al., 2011).

In order to assess the inter-coder reliability of the coding process, the two aforementioned researchers (J.R. and A.P.) coded all the selected studies (including methodological quality assessment), and, in case of disagreement between them, the third reviewer (A.L.) was consulted. Intra-class correlation coefficients were calculated (ICCs) for the quantitative moderator variables, while Cohen's kappa coefficients were applied for the qualitative moderator variables. On average, the ICC was 0.893 (range: $0.85-1.0$ ) and the kappa coefficient was 0.912 (range: 0.88 $1.0)$, which can be considered highly satisfactory, as proposed by Orwin and Vevea (2009). The codebook can be obtained from the corresponding author upon request.

Statistical analysis

For each of the three outcome measures (jumping performance, sprinting time and COD performance), an effect size was calculated using the standardized mean change (Gibbons et al., 1993) employing the standard deviation of the changes in the algorithm denominator. When a study did not report the standard deviation of the changes, an $r$ value equal to 0.7 was employed (Rosenthal, 1991). Furthermore, a correction factor proposed by Hedges (1981) was employed in order to avoid an overestimated effect size. Additionally, the same random sample of studies used in the coding reliability study was subjected to a double process of effect size calculations to assess the reliability of the effect size calculations, obtaining excellent inter-coder reliability, with intra-class correlations over 0.90 . Change in postintervention mean was calculated by subtracting baseline from post-intervention values. Change in the SD of the post intervention outcomes was calculated using the Review Manager (RevMan) computer program, version 5.3 (Nordic Cochrane Centre). Data required were: (1) $95 \%$ confidence interval data for pre-post intervention change for each group; (2) precise $p$ values (e.g. $p=0.76$ ); and (3) if these data were not forthcoming, we used default $p$ values: $p<.05$ became $p=0.049$, or $p<.01$ became $p=0.01$, and $p=\mathrm{NS}$ (non-significant) became $p=0.5$.

Separate meta-analyses were performed for each outcome measure. For each outcome, an average effect size $\left(D_{+}\right)$and a $95 \%$ confidence interval (CI) were calculated by assuming a random-effects model, with the inverse variance as the weighting factor (Sánchez-Meca and MarínMartínez, 2008). Heterogeneity of the effect sizes across studies was assessed by means of Cochrane $Q$ statistic and the $I^{2}$ index. A forest plot was also constructed for each meta-analysis. Lack of homogeneity was considered for Cochrane $Q$ tests with $p<0.10$ and/or for $I^{2}$ indices $\geq 50 \%$.

The forest plots were carried out with the Review Manager (RevMan) software package (version 5.3 for OSX, The Nordic Cochrane Centre, The Cochrane Collaboration, 2014, 
Copenhagen, Denmark).

\section{Results}

Study selection

A total of 1513 references were identified with all search strategies, from which 1456 were excluded in the first screening as duplicates or after reading the title and abstract. Next 48 studies did not fulfil the inclusion criteria for several reasons: they measured acute effects $(n=8)$, there was no control group $(n=16)$, no specific eccentric training $(n=7)$, no inertial training $(n=8)$, they measured other outcomes $(n=3)$, they studied an injured sample $(n=5)$ or included youth players $(n=1)$.

The search process enabled us to identify 9 articles that met the selection criteria for the qualitative analysis. Figure 1 shows the flow chart of the selection process of the studies.

Descriptive characteristics of the studies

The main characteristics of each of the integrated studies are presented in Table 1. The studies selected were carried out between 2003 and 2019. Six studies were carried out in Spain, one in the United Kingdom, one in Sweden and one in Poland. The total sample size was of 283 participants, 155 pertaining to the treatment groups and 128 to the control groups. Seven out of the nine trials included only males. Two included males and females. Three trials were performed with soccer players, two with handball players, one with both basketball and volleyball players, and three with recreational athletes. The mean age of participants in the samples was $21.7 \pm 2.2$ years.

Collectively, the length of the FRT interventions ranged from five to 24 weeks. The number of training sessions per week ranged from one to three. All the studies used lower body exercises (leg curl, leg extension, leg flexion, squat, leg press, lunges). Six of them trained bilaterally, whereas the other three used both bilateral and unilateral exercises.

Quality of the selected studies

The quality scores of each study are displayed in Appendix 3. The mean score obtained with the PEDro quality scale was 5.67 (minimum: 5, maximum: 6). None of the studies reported that allocation was concealed or that subjects, therapists or consultants were blinded. However, all studies clearly reported that participants completed $>85 \%$ of the intervention, and all studies conducted an intent-to-treat analysis, between-group analyses and provided point estimates for effect size.

Effect sizes

Jumping performance

Jumping performance was evaluated in seven studies (de Hoyo et al., 2015; Gual et al., 2016; Maroto-Izquierdo et al., 2017; MarotoIzquierdo et al., 2019; Naczk et al., 2016; Sabido et al., 2017; Tous-Fajardo et al., 2016), all by means of the countermovement jump (CMJ). The overall effect size showed a moderate and significant effect for FRT interventions. However, the heterogeneity found was high (SMC 0.65; 95\% CI, $0.11-1.19 ; p=0.02 ; \mathrm{I}^{2}=73 \%$; Figure 2a).

Sprinting time

Sprinting time was evaluated in five studies (Askling et al., 2003; de Hoyo et al., 2015; Maroto-Izquierdo et al., 2017; Sabido et al., 2017; Tous-Fajardo et al., 2016), three by means of a 20 $\mathrm{m}$ test, one through a $30 \mathrm{~m}$ test and one through a flying $30 \mathrm{~m}$ test. The overall effect size showed a high and significant effect for FRT interventions. The heterogeneity found was high (SMC 1.33; 95\% CI, 0.39-2.28; $p<0.01 ; I^{2}=80 \%$; Figure $2 b$ ).

Change of direction

Change of direction was evaluated in three studies (Maroto-Izquierdo et al., 2017; Monajati et al., 2018; Tous-Fajardo et al., 2016), one through a T-test, one through a V-cut test and one through a $4 \times 7.5 \mathrm{~m}$ shuttle sprint test. The overall effect size showed a high and significant effect for FRT interventions. The heterogeneity found was moderate (SMC 1.36; 95\% CI, 0.58-2.14; $p<0.01 ; \mathrm{I}^{2}=52 \%$; Figure 2c).

\section{Discussion}

The aim of this study was to analyze the efficacy of FRT in improving actions related to sport performance (jumping, sprinting and change of direction). The primary findings of the current work report the usefulness of FRT to enhance jumping ability, sprinting time and COD performance.

Although flywheel devices were originally created to be used in microgravity situations in order to reduce muscle mass loss (Alkner and Tesch, 2004; Alkner et al., 2003), there has been an exponential increase of this training methodology in sport populations during the last few years. A former meta-analysis showed FRT to 
be an effective tool to improve muscular power $(\mathrm{ES}=0.80[\mathrm{CI}=0.53,1.07])$. Thus, based on these findings and the evidence supporting the link between power production and dynamic athletic performance (Cormie et al., 2011), it would be logical that performance in sport activities can be improved after FRT interventions.
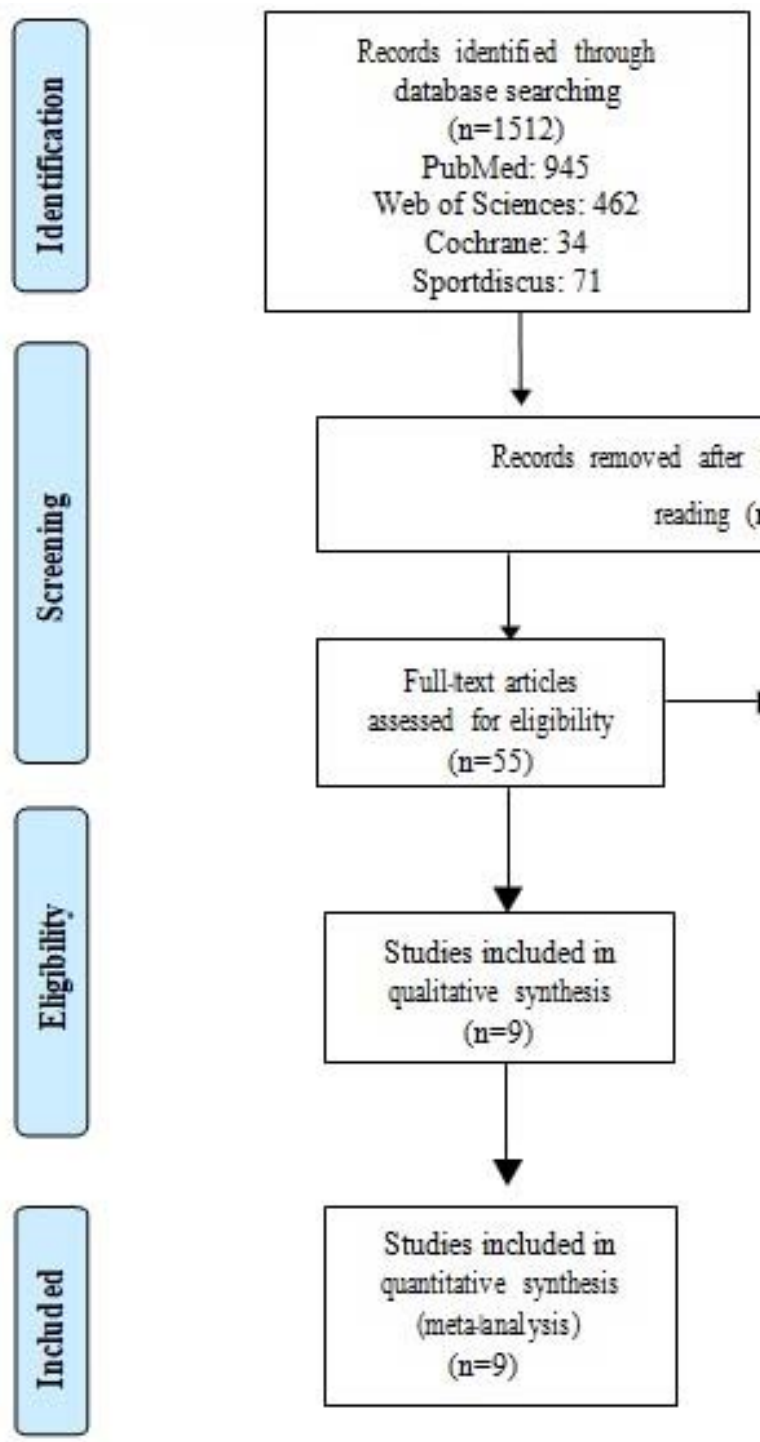

Sportdiscus: 71

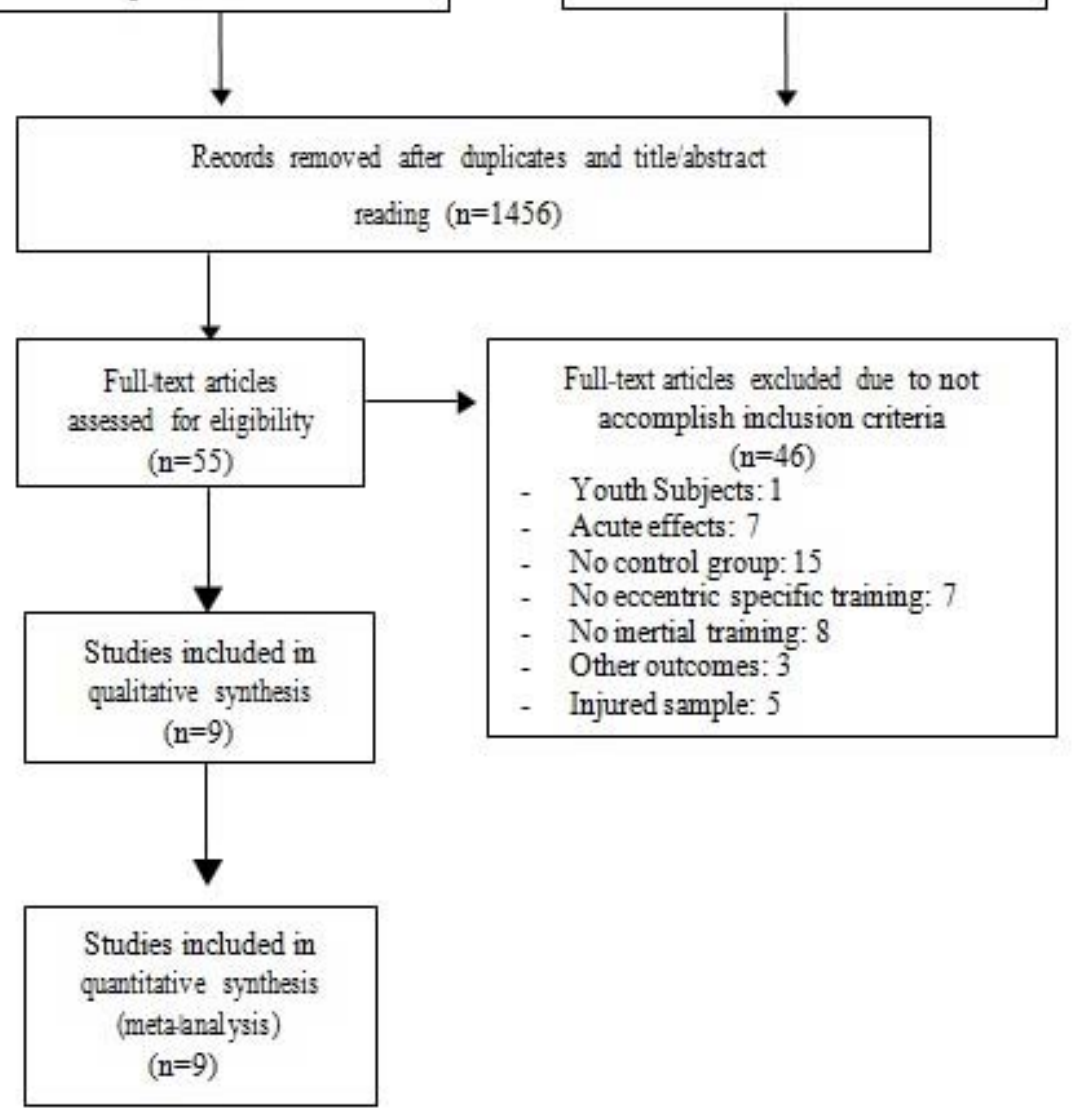

Figure 1
Additional records identified through other sources $(n=1)$ 
Table 1

Characteristics of the studies included in the meta-analysis

\begin{tabular}{|c|c|c|c|c|c|c|}
\hline Reference & Sample & $\begin{array}{l}\text { Muscle group / } \\
\text { Exercise } \\
\text { equipment }\end{array}$ & $\begin{array}{l}\text { Length } \\
\text { (Weeks) }\end{array}$ & Sessions & $\begin{array}{l}\text { Exercise training } \\
\text { characteristic }\end{array}$ & Outcome \\
\hline $\begin{array}{l}\text { Askling et al. } \\
(2003) \\
\text { Sweden }\end{array}$ & $\begin{array}{l}\text { Adult male } \\
\text { soccer } \\
\text { players } \\
\text { FTR: } 15 \\
\text { CG: } 15\end{array}$ & $\begin{array}{l}\text { Knee flexors/ } \\
\text { Yo-Yo leg curl }\end{array}$ & 10 & 16 & $\begin{array}{l}4 \text { sets of } 8 \text { reps/session } \\
\text { all out with both legs, } \\
\text { separated by } 1 \mathrm{~min} \text { of } \\
\text { rest. }\end{array}$ & $\begin{array}{l}\text { Significant increases in } \\
\text { running speed in the FRT } \\
\text { group. No training effects } \\
\text { in the control group. No } \\
\text { difference between } \\
\text { groups. }\end{array}$ \\
\hline $\begin{array}{l}\text { de Hoyo et al. } \\
(2015) \\
\text { Spain }\end{array}$ & $\begin{array}{l}\text { Junior soccer } \\
\text { players } \\
\text { FTR: } 18 \\
\text { CG: } 15\end{array}$ & $\begin{array}{l}\text { Knee extensors } \\
\text { and } \\
\text { flexors/ } \\
\text { Yo-Yo leg curl } \\
\text { and Yo-Yo squat }\end{array}$ & 10 & 15 & $\begin{array}{l}3-5 \quad \text { sets of } \quad 6 \\
\text { reps/session all out. } \\
\text { Half-squats and leg } \\
\text { curls. Flywheel device } \\
\text { with both legs. }\end{array}$ & $\begin{array}{l}\text { Significant increases in the } \\
\text { CMJ and running speed in } \\
\text { the FTR group. No } \\
\text { differences in the control } \\
\text { group. }\end{array}$ \\
\hline $\begin{array}{l}\text { Gual et al. } \\
(2016) \\
\text { Spain }\end{array}$ & $\begin{array}{l}\text { Adult Team } \\
\text { sport players } \\
\text { FTR: } 44 \\
\text { CG: } 37\end{array}$ & $\begin{array}{c}\text { Knee extensors/ } \\
\text { Yo-Yo squat }\end{array}$ & 24 & 24 & $\begin{array}{l}4 \text { sets of } 8 \text { reps/session } \\
\text { all out. Half-squats } \\
\text { with both legs } \\
\text { separated by } 2 \text { min of } \\
\text { rest. }\end{array}$ & $\begin{array}{l}\text { Significant increases in the } \\
\text { CMJ in the FRT group. } \\
\text { No differences in the } \\
\text { control group. }\end{array}$ \\
\hline $\begin{array}{l}\text { Maroto- } \\
\text { Izquierdo et al. } \\
\text { (2017) } \\
\text { Spain }\end{array}$ & $\begin{array}{l}\text { Professional } \\
\text { handball } \\
\text { players } \\
\text { FTR: } 15 \\
\text { CG: } 14\end{array}$ & $\begin{array}{l}\text { Knee extensors } \\
\text { and } \\
\text { flexors/ } \\
\text { Yo-Yo leg press }\end{array}$ & 6 & 15 & $\begin{array}{l}4 \text { sets of } 7 \text { reps/session } \\
\text { all out leg press. } \\
\text { Flywheel devices with } \\
\text { both legs, separated by } \\
3 \text { min of rest. }\end{array}$ & $\begin{array}{l}\text { Significant increases in the } \\
\text { CMJ, running speed and } \\
\text { the agility T-test. The } \\
\text { control group showed } \\
\text { smaller training effects in } \\
\text { running speed. }\end{array}$ \\
\hline $\begin{array}{l}\text { Maroto- } \\
\text { Izquierdo et al. } \\
\text { (2019) } \\
\text { Spain }\end{array}$ & $\begin{array}{l}\text { Active } \\
\text { university } \\
\text { students } \\
\text { FTR: } 10 \\
\text { CG: } 10\end{array}$ & Single-leg Squat & 6 & 12 & $\begin{array}{l}4 \text { sets of } 7 \text { reps/session } \\
\text { all out. Single leg } \\
\text { squats, flywheel } \\
\text { devices with the } \\
\text { dominant leg. }\end{array}$ & $\begin{array}{l}\text { The FTR group showed a } \\
\text { significant increase in the } \\
\text { bilateral CMJ. No } \\
\text { differences in the control } \\
\text { group. }\end{array}$ \\
\hline $\begin{array}{l}\text { Monajati et al. } \\
(2018) \\
\text { United } \\
\text { Kingdom }\end{array}$ & $\begin{array}{l}\text { Recreational } \\
\text { adult volleyball } \\
\text { players } \\
\text { FTR: } 10 \\
\text { CG: } 10\end{array}$ & $\begin{array}{l}\text { Knee extensors } \\
\text { and } \\
\text { flexors; hip } \\
\text { extensors/ } \\
\text { Yo-Yo leg curl, } \\
\text { Yo-Yo squat and } \\
\text { Versapulley }\end{array}$ & 6 & 12 & $\begin{array}{l}2 \text { sets of } 8 \text { reps/session } \\
\text { all out Half-squat } \\
\text { (bilateral, unilateral } \\
\text { and lunges), Yo-Yo } \\
\text { deadlift, Yo-Yo leg curl } \\
\text { and Versapulley hip } \\
\text { extension, separated by } \\
2 \text { min of rest. }\end{array}$ & $\begin{array}{l}\text { Significant increases in } \\
\text { Repeated Shuttle Sprint } \\
\text { Ability Test. }\end{array}$ \\
\hline $\begin{array}{l}\text { Naczk et al. } \\
\text { (2016) } \\
\text { Poland }\end{array}$ & $\begin{array}{l}\text { Male physical } \\
\text { education } \\
\text { students } \\
\text { FTR T0: } 19 \\
\text { FTR T10: } 18 \\
\text { CG C0: } 11 \\
\text { CG C10: } 10\end{array}$ & $\begin{array}{l}\text { Knee extensors/ } \\
\text { ITMS leg } \\
\text { extension }\end{array}$ & 5 & 15 & $\begin{array}{l}3 \text { sets of } 15 \text { reps/set } \\
\text { with } 19.4 \mathrm{~kg}(\mathrm{~T} 0) \text { and } \\
29.4 \mathrm{~kg}(\mathrm{~T} 10) \text { bilaterally, } \\
\text { separated by } 2 \text { min of } \\
\text { rest. }\end{array}$ & $\begin{array}{l}\text { Significant increases in } \\
\text { CMJ. No significant } \\
\text { differences } \\
\text { training groups. }\end{array}$ \\
\hline $\begin{array}{l}\text { Sabido et al. } \\
(2017) \\
\text { Spain }\end{array}$ & $\begin{array}{l}\text { Adult handball } \\
\text { players } \\
\text { FTR: } 11 \\
\text { CG: } 10\end{array}$ & $\begin{array}{c}\text { Knee extensors/ } \\
\text { K-box squat }\end{array}$ & 7 & 7 & $\begin{array}{l}\text { reps/session all out } \\
\text { half-squat with both } \\
\text { legs and lunge with } \\
\text { each leg, separated by } 2 \\
\text { min of rest. }\end{array}$ & $\begin{array}{l}\text { Both groups improved the } \\
20 \mathrm{~m} \text { sprint time and } \mathrm{CMJ} \\
\text { performance to a similar } \\
\text { extent. }\end{array}$ \\
\hline $\begin{array}{l}\text { Tous-Fajardo et } \\
\text { al. (2016) } \\
\text { Spain }\end{array}$ & $\begin{array}{l}\text { Elite junior } \\
\text { soccer players } \\
\text { FTR: } 12 \\
\text { CG: } 12\end{array}$ & $\begin{array}{l}\text { Knee extensors } \\
\text { and } \\
\text { flexors; hip } \\
\text { extensors and } \\
\text { obliques/ } \\
\text { Yo-Yo squat and } \\
\text { Versapulley }\end{array}$ & 11 & 11 & $\begin{array}{l}2 \quad \text { sets of } 6-10 \\
\text { reps/session all out } \\
\text { with each exercise, } \\
\text { separated by } 1-2 \text { min of } \\
\text { rest. }\end{array}$ & $\begin{array}{l}\text { Significant increases in } \\
\text { COD in the FTR group. } \\
\text { Significant increases in } \\
\text { CMJ in CG. Better } \\
\text { performance in } 10 \text { and } 30- \\
m \text { speed and COD for the } \\
\text { FRT group. }\end{array}$ \\
\hline
\end{tabular}

FTR: Flywheel resistance training. CG: Control group. Rep: repetitions.

ITMS: Inertial Training and Measurement System. CMJ: Countermovement Jump.

SJ: Squat Jump. COD: Change of direction 
a) Jumping performance

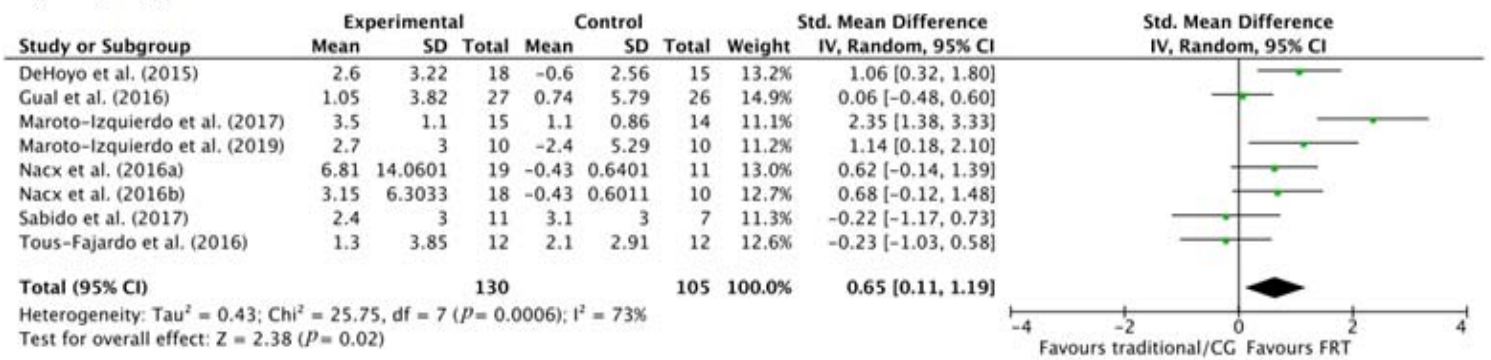

b) Sprinting performance

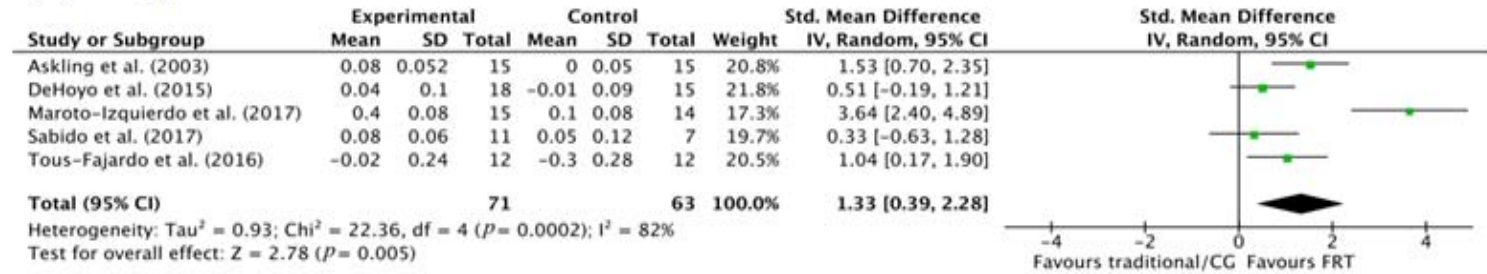

c) Change of direction performance

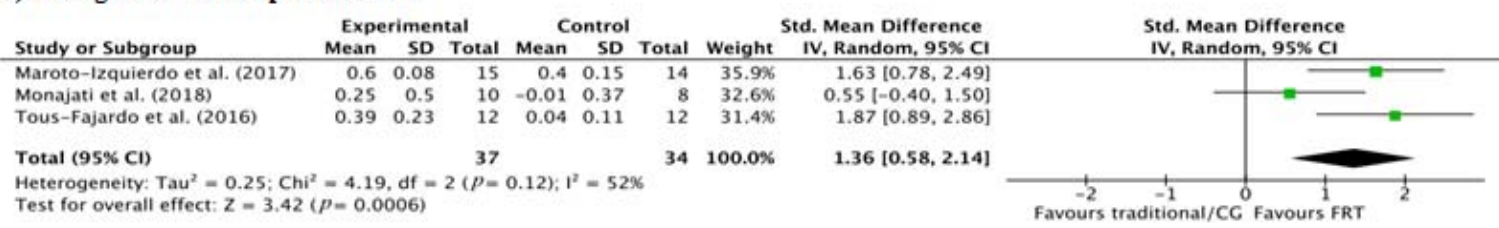

Figure 2

Forest plot with meta-analysis showing the efficacy of flywheel resistance training in enhancing jumping performance $(a)$, sprinting performance $(b)$

and change of direction ability $(c)$.

\section{Appendix 1. Search strategies.}

\section{Search strategy in PubMed: 945results}

\#1(Eccentric training[tiab] OR "Eccentric training"[MeSH Terms] OR eccentric overload[tiab] OR "eccentric overload"[MeSH Terms]OR resistance training[tiab] OR "resistance training"[MeSH Terms]OR flywheel[tiab] OR "flywheel"[MeSH Terms]) AND (sprint[tiab] OR "sprint"[MeSH Terms] OR change of direction[tiab] OR "change of direction"[MeSH Terms]OR jump[tiab] OR "jump"[MeSH Terms])

\#2 \#1 Filters: Published up to July 9 $9^{\text {th }}, 2019$.

\section{Search strategy in the Cochrane Central Register of Controlled Trials: 34 results}

\#1 Eccentric training [Title/Abstract/Key Word] OR flywheel [Title/Abstract/Key Word] AND sprint [Title/Abstract/Key Word] ORjump[Title/Abstract/Key Word] OR change of direction [Title/Abstract/Key Word]

\#2 \#1Filters: Published up to July 9th 2019 (by hand)

Search strategy in Web of Science: 462results

\#1 TI=(Eccentric training OR eccentric overload OR flywheel)

\#2 $\mathrm{TI}=$ (sprint $\mathrm{OR}$ change of direction OR jump)

\#3 \#2 AND \#1

Search strategy in Sportdiscus: 71 results

\#1 ('Eccentric training' OR 'eccentric overload' OR 'flywheel') AND ('sprint' OR ‘change of direction' OR 'jump') 


\section{Appendix2: Moderator variables codded.}

\section{Substantive variables}

Participants' characteristics:

- Number of participants of each group (traditional training/control and Flywheel resistance training).

- Age (years): average age of the total sample (FRT and traditional training/control groups together) and the mean age of FRT and traditional training/control groups.

- Sex: coded as males, females, and mixed, as the percentage difference between men in the FRT and traditional training/control groups.

- Previous experience in FRT.

Treatment characteristics

- Type of intervention (traditional training/control groups together, FRT).

- Duration of the program (weeks)

- Training sessions per week.

- Training sessions per day.

- Number of exercises.

- Type of exercise.

- Number of repetitions per exercise.

- Duration of each repetition in each exercise (seconds)

- Type of exercise (unilateral, bilateral).

- Intensity of each exercise.

\section{Methodological variables}

- Study design (randomized controlled trial or a cross-over study).

- Quality of the study (PEDro scale).

- Attrition in the post-test (percentage of participants in the final sample divided by the number of people in the initial sample).

\section{Extrinsic variables}

- Year of the study.

- Country. 
Appendix 3. Analysis of the selected studies' methodological quality (PEDro Scale).

\begin{tabular}{|c|c|c|c|c|c|c|c|c|c|c|c|c|}
\hline Study & 1 & 2 & 3 & 4 & 5 & 6 & 7 & 8 & 9 & $\begin{array}{l}1 \\
0\end{array}$ & $\begin{array}{l}1 \\
1\end{array}$ & $\begin{array}{l}S \\
c \\
o \\
r \\
e\end{array}$ \\
\hline $\begin{array}{c}\text { Askling et al. } \\
\text { (2003) }\end{array}$ & + & + & - & + & - & - & - & + & + & + & + & 6 \\
\hline $\begin{array}{c}\text { De Hoyo et al. } \\
\text { (2015) }\end{array}$ & + & + & - & + & - & - & - & + & + & + & + & 6 \\
\hline $\begin{array}{l}\text { Gual et al. } \\
\text { (2016) }\end{array}$ & + & + & - & + & - & - & - & + & + & + & + & 6 \\
\hline $\begin{array}{c}\text { Maroto- } \\
\text { Izquierdo et al. } \\
\text { (2017) }\end{array}$ & + & + & - & + & - & - & - & + & + & + & + & 6 \\
\hline $\begin{array}{c}\text { Monajati et al., } \\
\text { (2018) }\end{array}$ & + & + & - & + & - & - & - & + & + & + & + & 6 \\
\hline $\begin{array}{c}\text { Naczk et al. } \\
\text { (2016) }\end{array}$ & - & + & - & + & - & - & - & + & + & + & + & 6 \\
\hline $\begin{array}{l}\text { Sabido et al. } \\
\text { (2017) }\end{array}$ & + & - & - & + & - & - & - & + & + & + & + & 5 \\
\hline $\begin{array}{l}\text { Tous-Fajardo et } \\
\text { al. (2016) }\end{array}$ & + & - & - & + & - & - & - & + & + & + & + & 5 \\
\hline $\begin{array}{c}\text { Maroto- } \\
\text { Izquierdo et al. } \\
\text { (2019) }\end{array}$ & + & + & - & - & - & - & - & + & + & + & + & 5 \\
\hline
\end{tabular}

The numbers of the columns corresponded to the following items of the PEDro scale.

1. Eligibility criteria were specified (not included in the score).

2. Subjects were randomly allocated to groups.

3. Allocationwas concealed.

4. The groups were similar at baseline regarding the most important prognostic indicator.

5. There was blinding of all subjects.

6. There was blinding of all therapists who administered the therapy.

7. There was blinding of all consultants who measured at least one key outcome.

8. Measures of at least one key outcome were obtained from more than $85 \%$ of the subjects initially allocated to groups.

9. All subjects for whom outcome measures were available received the treatment or control condition as allocated or, in those situations in which this was not the case, data for at least one key outcome was analyzed by intention to treat.

10. The results of between-group statistical comparisons were reported for at least one key outcome.

11. The study provided both point measures and measures of variability for at least one key outcome. 
One of the most important variables regarding sport performance is the sprint. The results of the present study agree with a previous meta-analysis in which significant improvements in sprinting time were reported after a FRT intervention (ES $=0.41$; CI $[0.00,0.82]$ ) (MarotoIzquierdo et al., 2017). Sprinting time showed a great decrease following FRT interventions ( $p<$ $0.01 ; \mathrm{ES}=1.23[\mathrm{CI}=0.35,2.12])$ in the present study. It should be highlighted that improvements in sprint tests have been reported even when a wide variety of exercises during FRT interventions were employed. For example, among the exercises used in the different studies analyzed, we saw the squat exercise (De Hoyo et al., 2015; Sabido et al., 2017), the leg curl exercise (Askling et al., 2003; de Hoyo et al., 2015), the leg press exercise (Maroto-Izquierdo et al., 2017) and a multi-exercise program (Tous-Fajardo et al., 2016) among others. This fact reflects the efficacy of FRT to improve sprinting time, in spite of the exercises used during training. The only study reporting negative results in sprint performance after a FRT intervention (Raya-González et al., 2018) was excluded from the analysis. This exclusion was made based on methodological reasons. On the one hand, the study by RayaGonzález et al. (2018) included young participants $(\approx 14$ years) with no experience in resistance training. This fact is crucial, as proper experience with flywheel exercises facilitates the improvements obtained after a FRT intervention (Nuñez-Sánchez and Saez de Villarreal, 2017). In addition, participants were not instructed to delay the braking action to the last part of the ECC action during training. This specific instruction is a key point when using flywheel devices, as EO is dependent on this delayed braking action, and force gains after FRT interventions are linked to the EO created during the exercise (NuñezSánchez and Saez de Villarreal, 2017). Although the large magnitude of change is influenced by the huge effect size found in the study by MarotoIzquierdo et al. (2017), it should be noted that, even when such a study was excluded from the analysis, FRT caused significant improvements in sprinting time $(\mathrm{p}=0.0003 ; \mathrm{ES}=0.74 ; \mathrm{CI}[0.34$, 1.14]). A potential explanation of the improvements in sprinting performance after FRT interventions is related to specific muscular adaptations. Precisely, FRT interventions have shown to increase mRNA levels of type II fibers (Friedmann-Bette et al., 2010), potentially inducing a faster muscle phenotype, which favors explosive actions.

Along with sprinting, jumping ability is another variable of high interest when evaluating sport performance. Jumping ability, which was assessed through the countermovement jump test, showed a significant moderate effect $(p=0.02$; ES $=0.65[95 \% \quad \mathrm{CI}=0.11,1.19])$ after FRT interventions. The results of the present metaanalysis do not only agree with those reported by Maroto-Izquierdo et al. (2017) (ES = 0.46 [95\% CI = $0.09,0.83])$, but they also increase the statistical power (from 70 to 130 participants) and the magnitude of performance change from 0.46 (small) to 0.65 (moderate). Nevertheless, some studies showed no favorable results for FRT groups. These discrepancies in jumping ability improvements found in the studies may be mainly explained by differences in training frequency. When looking specifically at each work, the articles presenting non-favorable results after a FRT intervention were those in which only one session per week was performed (Gual et al., 2015; Sabido et al., 2017; Tous-Fajardo et al., 2016). Contrarily, those showing favorable results for FRT interventions used a schedule of 2-3 sessions per week (de Hoyo et al., 2015; Maroto-Izquierdo et al., 2017, 2019; Naczk et al., 2016). Thus, it seems that a training frequency of at least two sessions per week promotes jumping performance optimization. The great efficacy of FRT in the improvement of jumping performance is explained by the nature of flywheel devices. Thus, during flywheel exercises, the great amount of kinetic energy produced during the CON action must be counteracted by an ECC action that requires a very high force production. This EO may be an optimal stimulus for adaptations related to jumping ability, such as improvements in the stretch-shortening cycle and muscle-tendon unit stiffness (Roig et al., 2009). In addition, it can be hypothesized that FRT entails specific adaptations in the ECC phase (e.g., greater eccentric velocities) (de Hoyo et al., 2016), and these specific changes in the movement pattern are related to subsequent improvements in the CON action (Cormie et al., 2010).

This is the first meta-analysis in which the effects of FRT on COD ability have been 
evaluated. It remains crucial to optimize COD performance, since frequent variations in directional changes have been reported during competitive team-sport matches (Chaouachi et al., 2012). In fact, several authors have suggested a good COD ability to be a requisite for success in modern-day sports (Brughelli et al., 2008). Our results herein showed the greatest overall effect $(\mathrm{ES}=1.37[95 \% \mathrm{CI}=0.62,2.12])$, highlighting the usefulness of FRT for the enhancement of COD performance. Furthermore, COD improvements have been reported in a wide variety of tests that included COD of $45^{\circ}$ (Tous-Fajardo et al., 2016), $90^{\circ}$ (Maroto-Izquierdo et al., 2017) and $180^{\circ}$ (Maroto-Izquierdo et al., 2017; Monajati et al., 2018). In addition, these COD improvements have been consistently reported independent of the FRT used in these previous studies, which were quite different: flywheel leg press exercise (Maroto-Izquierdo et al., 2017) or a multi-exercise program (6-8 exercises), sharing only two exercises (unilateral hamstring kicks and lateral squats) (Monajati et al., 2018; Tous-Fajardo et al., 2016). Altogether, these data support FRT as an optimal stimulus to improve COD performance. This could be due to the fact that flywheel devices allow to perform not only more specific (than traditional) exercises, but also multi-planar exercises (Gonzalo-Skok et al., 2016), being possible to use both bilateral and unilateral exercises emphasizing the ECC phase. Thus, De Hoyo et al. (2016) found significant changes in the contact time and in the time spent during braking when performing COD after a FRT intervention. As previous research has identified the ECC phase as a key point to improve the subsequent acceleration phase (Spiteri et al., 2013), changes in the braking action could positively influence the subsequent propulsive phase, being potentially responsible for COD performance improvements. These improvements should be emphasized, as a meta-analysis of COD ability reported that most of the traditional resistance training methods (e.g., Olympic weightlifting, plyometrics) failed to elicit COD improvements (Brughelli et al., 2008).

In conclusion, the results of the present systematic review and meta-analysis showed that FRT is an effective tool to improve performance in actions related to sport success in healthy active people and competitive athletes. It must be highlighted that these improvements are achieved using short (5-10 weeks) training interventions. In addition, jumping performance, sprinting time, and especially COD performance are susceptible to improve after a FRT intervention. The efficacy of FRT in improving sport actions can be explained by increases in muscular strength, muscle size, and greater forces achieved during the eccentric muscular action among others. Changes in the pattern (greater velocities) of the eccentric phase of the movements (braking action during a COD) are also responsible for performance improvements after FRT. In consequence, the storage and utilization of elastic energy increase, which maximizes the propulsive force applied in the subsequent concentric action, leading to a faster acceleration. In addition, flywheel devices allow the use of multi-planar and more specific movements than traditional resistance training methodologies, which based on the training specificity theorem, causes a greater transfer to sport actions. Nevertheless, it seems that a single session per week is not a sufficient stimulus to improve jumping performance. In spite of the promising results, future studies are needed to increase the statistical power, also allowing the comparison between different types of FRT. To conclude, specific FRT characteristics (volume, inertial load, exercises used) should be specified in order to determine the dose-response that maximizes the improvements in a given sport action.

\section{Limitations}

The main limitation of this study is the relatively small number of articles published which could be included in this meta-analysis, although positive effects have been shown with this limited number of studies. In addition, heterogeneity within the studies included in the analysis was high, since participants' age or resistance training experience differed. Moreover, the wide variety of exercise interventions (intervention duration, exercises used, volume, intensity), may have also influenced the results obtained in the meta-analysis. This fact makes it impossible to detect any qualitative moderator variables (e.g., inertial load used, training frequency) for the effect size found. Therefore, more homogeneous studies should be carried out for a better understanding of performance adaptations following FRT interventions. Finally, there is a lack of articles assessing the 
effectiveness of FRT compared with traditional resistance training. Future studies should investigate this comparison, as it is of significant practical use for strength and conditioning coaches.

\section{Acknowledgments}

Javier Raya-González gratefully acknowledges the support of a Spanish government subproject Mixed method approach on performance analysis (in training and competition) in elite and academy sport [PGC2018-098742-B-C33] (2019-2021), from Ministerio de Ciencia, Innovación y Universidades (MCIU), Agencia Estatal de Investigación (AEI), and Fondo Europeo de Desarrollo Regional (FEDER), that is part of the coordinated project New approach of research in physical activity and sport from mixed methods perspective (NARPAS_MM) [SPGC201800X098742CV0].

\section{References}

Alkner BA, Berg HE, Kozlovskay, I, Sayenko D, Tesch PA. Effects of strength training, using a gravityindependent exercise system, performed during 110 days of simulated space station confinement. Eur J ApplPhysiol,2003; 90(1-2): 44-49

Alkner BA, Tesch PA. Efficacy of a gravity-independent resistance exercise device as a countermeasure to muscle atrophy during 29-day bed rest. Acta Physiol Scand, 2004; 181(3): 345-357

Askling C, Karlsson J, Thorstensson A. Hamstring injury occurrence in elite soccer players after preseason strength training with eccentric overload. Scand J Med Sci Sports, 2003; 13(4): 244-250

Berg HE, Tesch A. A gravity-independent ergometer to be used for resistance training in space. Aviat Space Environ Med, 1994; 65(8): 752-756

Brughelli M, Cronin J, Levin G, Chaouachi A. Understanding change of direction ability in sport. Sport Med, 2008; 38(12): 1045-1063

Chaouachi A, Manzi V, Chaalali A, Wong del P, Chamari K, Castagna C. Determinants analysis of changeof-direction ability in elite soccer players. J Strength Cond Res, 2012; 26(10): 2667-2676

Cormie P, McGuigan MR, Newton RU. Changes in the eccentirc phase contribute to improved stretchshortening cycle performance after training. Med Sci Sport Exerc, 2010; 42(9): 1731-1744

Cormie P, McGuigan MR, Newton RU. Developing maximal neuromuscular power. Sport Med, 2011; 41(2): $125-146$

de Hoyo M, de la Torre A, Pradas F, Sañudo B, Carrasco L, Mateo-Cortes J, Domínguez-Cobo S, Fernandes $\mathrm{O}$, Gonzalo-Skok O. Effects of eccentric overload bout on change of direction and performance in soccer players. Int J Sports Med, 2015; 36(4): 308-314

de Hoyo M, Gonzalo-Skok O, Sañudo B, Carrascal C, Plaza-Armas JR, Camacho-Candil F, Otero-Esquina C. Comparative effects of in-season full-back squat, resisted sprint training, and plyometric training on explosive performance in u-19 elite soccer players. J Strength Cond Res, 2016; 30(2): 368-377

De Hoyo M, Pozzo M, Sanudo B, Carrasco L, Gonzalo-Skok O, Domínguez-Cobo S, Morán-Camacho E. Effects of a 10-week in-season eccentric overload training program on muscle injury prevention and performance in junior elite soccer players. Int J Sport Physiol Perform, 2015; 10: 46-52

de Hoyo M, Sañudo B, Carrasco L, Domínguez-Cobo S, Mateo-Cortes J, Cadenas-Sánchez MM, Nimphius S. Effects of traditional versus horizontal inertial flywheel power training on common sport-related tasks. J Hum Kinet, 2015; 47(1): 155-167

de Hoyo M, Sañudo B, Carrasco L, Mateo-Cortes J, Domínguez-Cobo S, Fernandes O, Del Ojo JJ, GonzaloSkok O. Effects of 10-week eccentric overload training on kinetic parameters during change of direction in football players. J Sports Sci, 2016; 34(14): 1380-1387

Fernandez-Gonzalo R, Lundberg TR, Alvarez-Alvarez L, De Paz JA. Muscle damage responses and adaptations to eccentric-overload resistance exercise in men and women. Eur J Appl Physiol, 2014; 114(5): 1075-1084 
Friedmann-Bette B, Bauer T, Kinscherf R, Vorwald S, Klute K, Bischoff D, Müller H, Weber MA, Metz J, Kauczor HU, Bärtsch P, Billeter R. Effects of strength training with eccentric overload on muscle adaptation in male athletes. Eur J Appl Physiol, 2010; 108(4): 821-836

Gibbons RD, Hedeker DR, Davis JM. Estimation of effect size from a series of experiments involving paired comparisons. J Educ Stat, 1993; 18(3): 271-279

González-Badillo JJ, Pareja-Blanco F, Rodríguez-Rosell D, Abad-Herencia JL, Del Ojo-López JJ, SánchezMedina L. Effects of velocity-based resistance training on young soccer players of different ages. $J$ Strength Cond Res, 2015; 29(5): 1329-1338

Gonzalo-Skok O, Tous-Fajardo J, Valero-Campo C, Berzosa C, Bataller AV, Arjol-Serrano JL, Moras G, Mendez-Villanueva A. Eccentric-overload training in team-sport functional performance: constant bilateral vertical versus variable unilateral multidirectional movements. Int J Sports Physiol Perform, 2017; 12(7): 951-958

Gual G, Fort-Vanmeerhaeghe A, Romero-Rodríguez D, Tesch PA. Effects of in-season inertial resistance training with eccentric overload in a sports population at risk for patellar tendinopathy. J Strength Cond Res, 2016; 30(7): 1834-1842

Häkkinen K, Komi PV, Alén M. Effect of explosive type strength training on isometric force- and relaxationtime, electromyographic and muscle fibre characteristics of leg extensor muscles. Acta Physiol Scand, 1985; 125(4): 587-600

Hedges LV. Distribution theory for glass's estimator of effect size and related estimators. J Educ Stat, 1981; 6(2): 107-128

Lipsey MW. The primary factors that characterize effective interventions with juvenile offenders: a metaanalytic overview. Vict Offender, 2009; 4(2): 124-147

Maroto-Izquierdo S, García-López D, de Paz JA. Functional and muscle-size effects of flywheel resistance training with eccentric-overload in professional handball players. J Hum Kinet, 2017; 60(1): 133-143

Maroto-Izquierdo S, García-López D, Fernandez-Gonzalo R, Moreira OC, González-Gallego J, de Paz JA. Skeletal muscle functional and structural adaptations after eccentric overload flywheel resistance training: a systematic review and meta-analysis. J Sci Med Sport, 2017; 20(10): 943-951

Maroto-Izquierdo S, Fernandez-Gonzalo R, Magdi HR, Manzano-Rodriguez S, González-Gallego J, de Paz JA. Comparison of the musculoskeletal effects of different iso-inertial resistance training modalities: Flywheel vs. electric-motor. Eur J Sport Sci, 2019; 6: 1-11

Moher D, Liberati A, Tetzlaff J, Altman DG, PRISMA Group. Preferred reporting items for systematic reviews and meta-analyses: The PRISMA Statement. PLoS Med, 2009; 6(7): e1000097

Monajati A, Larumbe-Zabala E, Goss-Sampson M, Nacleiro F. Injury prevention programs based on flywheel vs. body weight resistance in recreational athletes. J Strength Cond Res, 2018; doi:10.1519/JSC.0000000000002878

Naczk M, Naczk A, Brzenczek-Owczarzak W, Arlet J, Adach Z. Impact of inertial training on strength and power performance in young active men. J Strength Cond Res, 2016; 30(8): 2107-2113

Norrbrand L, Fluckey JD, Pozzo M, Tesch PA. Resistance training using eccentric overload induces early adaptations in skeletal muscle size. Eur J Appl Physiol, 2008; 102(3): 271-281

Nuñez FJ, Sáez de Villarreal E. Does flywheel paradigm training improve muscle volume and force? A MetaAnalysis. J Strength Cond Res, 2017; 31(11): 3177-3186

Núñez FJ, Santalla A, Carrasquila I, Asian JA, Reina JI, Suarez-Arrones LJ. The effects of unilateral and bilateral eccentric overload training on hypertrophy, muscle power and COD performance, and its determinants, in team sport players. PLoS One, 2018; 13(3): e0193841

Núñez FJ, Suarez-Arrones LJ, Cater P, Mendez-Villaneva A. The high-pull exercise: a comparison between a versapulley flywheel device and the free weight. Int J Sports Physiol Perform, 2017; 12(4): 527-532

Orwin RG, Vevea JL. Evaluating coding decisions. In The Handbook of Research Synthesis and Meta-Analysis. $2^{\text {nd }}$ ed, New York US; Russell Sage Foundation; 2009

Raya-González J, Suarez-Arrones LJ, Risquez-Bretones AJ, Saez de Villarreal E. Short-term effects of an eccentric-overload training program on the physical performance on U-16 elite soccer. Retos. Educ Física y Deporte, 2018; 33: 106-111 
Roig M, O'Brien K, Kirk G, Murray R, McKinnon P, Shadgan B, Reid WD. The effects of eccentric versus concentric resistance training on muscle strength and mass in healthy adults: a systematic review with meta-analysis. Br J Sports Med, 2009; 43(8): 556-568

Romero-Rodriguez D, Gual G, Tesch PA. Efficacy of an inertial resistance training paradigm in the treatment of patellar tendinopathy in athletes: a case-series study. Phys Ther Sport, 2011; 12(1): 43-48

Rosenthal R. Applied social research methods series. In Meta-Analytic procedures for social research. Thousand Oaks, CA, US; SAGE Publications, Inc.; 1991

Sabido R, Hernández-Davó JL, Botella J, Navarro A, Tous-Fajardo J. Effects of adding a weekly eccentricoverload training session on strength and athletic performance in team-handball players. Eur J Sport Sci, 2017; 17(5): 530-538

Sánchez-Meca J, Marín-Martínez F. Confidence intervals for the overall effect size in random-effects metaanalysis. Psychol Methods, 2008; 13(1): 31-48

Sherrington C, Herbert RD, Maher CG, Moseley AM. PEDro. A database of randomized trials and systematic reviews in physiotherapy. Man Ther, 2000; 5(4): 223-226

Spiteri T, Cochrane JL, Hart NH, Haff GG, Nimphius S. Effect of strength on plant foot kinetics and kinematics during a change of direction task. Eur J Sport Sci, 2013; 13(6): 646-652

Suchomel TJ, Nimphius S, Bellon CR, Stone MH. The importance of muscular strength: training considerations. Sport Med, 2018; 48(4): 765-785

Swinton PA, Lloyd R, Keogh JWL, Agouris I, Stewart AD. Regression models of sprint, vertical jump, and change of direction performance. J Strength Cond Res, 2014; 28(7): 1839-1848

Tesch PA, Ekberg A, Lindquist DM, Trieschmann JT. Muscle hypertrophy following 5-week resistance training using a non-gravity-dependent exercise system. Acta Physiol Scand, 2004; 180(1): 89-98

Tous-Fajardo J, Gonzalo-Skok O, Arjol-Serrano JL, Tesch P. Enhancing change-of-direction speed in soccer players by functional inertial eccentric overload and vibration training. Int J Sports Physiol Perform, 2016; 11(1): 66-73

Valkenet K, van de Port IG, Dronkers JJ, de Vries WR, Lindeman E, Backx FJ. The effects of preoperative exercise therapy on postoperative outcome: a systematic review. Clin Rehabil, 2011; 25(2): 99-111

Vicens-Bordas J, Esteve E, Fort-Vanmeerhaeghe A, Bandholm T, Thorborg K. Is inertial flywheel resistance training superior to gravity-dependent resistance training in improving muscle strength? A systematic review with meta-analyses. J Sci Med Sport, 2018; 21(1): 75-83

Wisløff U, Castagna C, Helgerud J, Jones R, Hoff J. Strong correlation of maximal squat strength with sprint performance and vertical jump height in elite soccer players. Br J Sports Med, 2004; 38(3): 285-288

\section{Corresponding authors:}

\section{Jose Luis Hernández-Davó}

Faculty of Health Sciences, Isabel I University, Burgos, Spain

E-mail: jlhdez43@gmail.com;

\section{Amaya Prat-Luri}

Department of Sport Sciences, Sport Research Center, Miguel Hernández University, Elche, Spain E-mail: aprat@umh.es 